\title{
The State of Copper in Human Serum: Evidence for an Amino Acid-bound Fraction*
}

\author{
Peter Z. Neumann † and Andrew Sass-Kortsak $\ddagger$ \\ (From the Department of Paediatrics, Faculty of Medicine, University of Toronto, and The \\ Research Institute, The Hospital for Sick Children, Toronto, Ontario, Canada)
}

\begin{abstract}
Summary. In addition to copper bound to ceruloplasmin and to albumin, there is a third small fraction of copper in human serum that is bound to amino acids. The amino acid-bound fraction of copper is in equilibrium with albumin-bound copper, and both fractions are probably in equilibrium with ionic copper.

Of the 23 amino acids that are known to be in human serum, a substantial number were shown (in physiological concentrations) to compete effectively with albumin for the binding of copper. In this respect, histidine had the most marked effect followed by glutamine, threonine, cystine, and others. The effect of the combined presence of 23 amino acids on the state of copper in human serum could not be explained on the basis of their individual abilities to compete with albumin for the binding of copper. It is suggested that copper may also be present in serum in the form of mixed amino acid-copper complexes consisting of one atom of copper and two different amino acids. Under normal conditions, histidine is the amino acid primarily involved in the formation of mixed amino acid-copper complexes in serum. In combination with histidine and copper, threonine, glutamine, and asparagine are the other amino acids that are most likely to be the third members of these mixed complexes.

The first binding site for copper on human albumin is different from subsequent ones in that its binding affinity to copper is much higher. We propose that the amino acid-bound fraction of copper in serum may have a physiological role in the biological transport of copper.
\end{abstract}

\section{Introduction}

Normal human plasma contains close to $1 \mu \mathrm{g}$ of copper per ml. A large fraction of this (approximately 93\%) is bound to ceruloplasmin

* Submitted for publication May 31, 1966; accepted December 30, 1966.

Supported by funds from The Medical Research Council of Canada.

A preliminary report of this investigation was presented at the Seventeenth Scientific Meeting of the Protein Foundation, Cambridge, Mass., and published in Vox Sang. (Basel), 1963, 8, 111.

† Senior Research Fellow, The Research Institute, The Hospital for Sick Children, Toronto.

$\ddagger$ Address requests for reprints to Dr. Andrew SassKortsak, 555 University Avenue, Toronto, Ontario, Canada.
(1-3). The copper in this compartment is not in equilibrium with ionic copper in vitro and is not exchangeable in vivo $(2,4)$. A smaller fraction, comprising about $7 \%$ of the copper in plasma, is bound to albumin $(2,3)$. This latter fraction is in rapid equilibrium with tissue copper (5), and is considered to be the immediate transport form of copper in plasma.

It is logically assumed that the albumin-bound copper in plasma is in equilibrium with ionic copper (6). Earl, Moulton, and Selverstone found that 0.2 to $0.4 \%$ of an unspecified amount of labeled copper added in vitro to human serum was ultrafilterable (7). However, measurements of the probably extremely low concentrations of ionic copper in plasma have not been reported. 
TABLE I

List of L-amino acids used in this study and the upper limit of their concentrations in normal human plasma (11)

\begin{tabular}{lclc}
\hline \multicolumn{1}{c}{ Amino acid } & $\begin{array}{c}\text { Upper limit } \\
\text { ofnormal } \\
\text { concen- } \\
\text { tration }\end{array}$ & \multicolumn{1}{c}{ Amino acid } & $\begin{array}{c}\text { Upper limit } \\
\text { of normal } \\
\text { concen- } \\
\text { tration }\end{array}$ \\
\hline Asparagine & $m g / 100 m l$ & & $m g / 100 ~ m l$ \\
Glutamic acid & 1.4 & Methionine & 0.9 \\
Glutamine & 4.4 & Proline & 2.9 \\
Glycine & 9.7 & Phenylalanine & 1.9 \\
Alanine & 2.8 & Tyrosine & 1.5 \\
a-Amino butyric acid & 4.2 & Tryptophan & 1.7 \\
Valine & 0.3 & Histidine & 2.1 \\
Leucine & 3.4 & 1-Methyl histidine & 0.17 \\
Isoleucine & 2.4 & Ornithine & 0.8 \\
Serine & 1.8 & Lysine & 3.0 \\
Threonine & 1.3 & Arginine & 2.5 \\
Cystine & 3.1 & Citrulline & 0.5 \\
\hline
\end{tabular}

In this paper, evidence will be presented that nonprotein-bound copper is present in human serum and that most of this third fraction of copper is bound to amino acids.

\section{Methods}

To avoid contamination with copper, we soaked all glassware and syringes in $10 \%$ nitric acid and extensively rinsed them in deionized water. ${ }^{1}$ Chemicals were of the highest degree of purity; solutions were prepared with ion-free water.

Venous blood was collected from healthy young adult donors after an overnight fast. The blood was allowed to clot. The serum was separated by centrifugation, kept at $4^{\circ} \mathrm{C}$, and used within 3 days. To remove small molecular size solutes, we dialyzed the serum at $4^{\circ} \mathrm{C}$ with constant mixing for 48 hours against four to six changes of 15 to 20 times the volume of isotonic sodium chloride solution, adjusted to $\mathrm{pH} 7.4 \pm 0.1$ with dilute sodium hydroxide. After this treatment, we designated the serum "predialyzed serum" to distinguish it from "native serum," which was not dialyzed.

The total protein content of the sera was determined by a biuret method (8). The serum albumin levels were measured after the precipitation of the globulins by sodium sulfite (9). The slightly higher concentration of protein in the native sample of serum was adjusted to the somewhat lower concentration in the predialyzed sample by addition of neutralized physiological saline

Purified human serum albumin was used in some experiments. $^{2}$ A $4 \mathrm{~g}$ per $100 \mathrm{ml}$ solution of this was pre-

1 Illco-Way ion exchanger, research model, Illinois Water Treatment Co., Rockford, Ill.

2 This was prepared by the Connaught Medical Research Laboratories in Toronto from outdated human plasma collected by the Canadian Red Cross Society from volunteer donors. The preparation was kindly donated to us through the courtesy of Dr. A. M. Fisher. pared in neutralized physiological saline. This was extensively dialyzed under the conditions specified for serum. In the resulting solution, the total protein content was measured as specified above; the method of Eden and Green was used to determine the copper content (10).

The amino acids that we used are listed in Table $I$. These were added to the sera or to the albumin solution in a small volume of neutralized saline, usually in amounts sufficient to achieve final concentrations at the upper limit of the normal physiological range in human plasma (11). These concentrations are also shown in Table I.

Copper was added in the form of cupric acetate or chloride, and the amounts added were expressed in terms of the final molar ratio of copper to albumin. The physiologically low concentrations of nonceruloplasmin-bound (direct reacting) copper that were present in the sera before the addition of copper were not determined for two reasons. At the higher $\mathrm{Cu} / \mathrm{alb}$ molar ratios (0.1 to 5.0$)$, the small amounts of copper normally present in this compartment $(\mathrm{Cu} / \mathrm{alb}=0.002)$ were negligible. Secondly, the only method available for the measurement of direct reacting copper in serum (2) is of limited accuracy; therefore, at the physiological low levels of copper, it appeared safer to accept and use the average normal figure that was established on the basis of measurements in 30 normal human sera (3) than to base the calculations on inaccurate direct measurements.

Radioactive ${ }^{64} \mathrm{Cu}$ was used as a label. In most of the experiments, a commercially available sterile solution of ${ }^{64} \mathrm{Cu}$ acetate was used. ${ }^{3}$ In some of the experiments, a preparation of ${ }^{64} \mathrm{Cu}$ chloride of high specific activity (10 to $20 \mathrm{mc}$ per $\mu \mathrm{g}$ ) was used 4 (12). When necessary, nonradioactive cupric acetate was added to the ${ }^{\circ 4} \mathrm{Cu}$ solutions. To avoid the precipitation of protein upon addition of the acid copper solutions to the sera or to the albumin solutions, we adjusted the $\mathrm{pH}$ of the former to 4.5 to 5.0. At this $\mathrm{pH}$, the copper remained in solution and precipitation of protein did not occur.

The general design of the experiments was as follows. Measured portions usually of $7.0 \mathrm{ml}$ of native or predialyzed serum or albumin solution were placed in $25-\mathrm{ml}$ glass beakers. After this, when applicable, the amino acids or other low molecular weight constituents of serum were added. Fatty acids were added in a small volume of ethyl alcohol, and, in this case, controls with alcohol were included. After this, labeled copper solution was added that contained various predetermined amounts of copper in less than $0.5 \mathrm{ml}$ volume. The contents of the beakers were mixed, and the $\mathrm{pH}$ was adjusted individually to $7.4 \pm 0.1$ with an electric $\mathrm{pH}$ meter equipped with micro glass electrodes, using $0.1 \mathrm{~N}$ hydrochloric acid or $0.1 \mathrm{~N}$ sodium hydroxide from a microburette. The volumes of the required additions were carefully noted. The total volume contained in the beakers was then calculated as the sum of the volume of the protein solutions and the volumes of the various additions. The volume

3 Abbott Radiopharmaceuticals, Oak Ridge, Tenn.

4 Obtained from McMaster University, Hamilton, Ontario. 


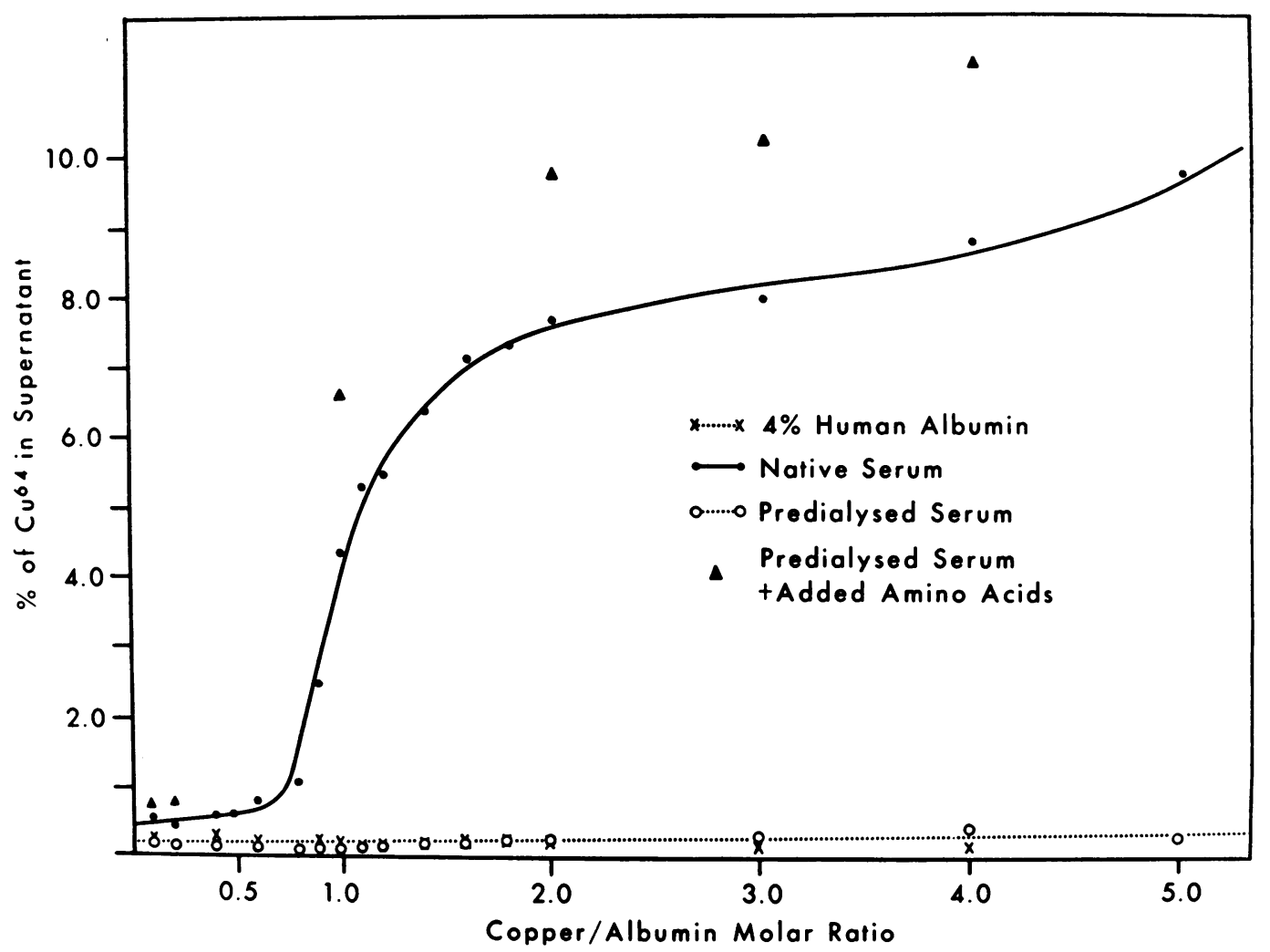

Fig. 1. Per cent of added ${ }^{64} \mathrm{Cu}$ in the supernatant after Ultracentrifugal sedimentation of pRoteins plotted aGainst Copper/albumin (CU/ALb) MOlar Ratio.

of fluid in each beaker was then adjusted to a constant volume with neutralized physiological saline. The total volume of the contents of the beakers rarely exceeded $8.5 \mathrm{ml}$.

The separation of protein and nonprotein-bound copper was achieved by centrifugation in a Spinco model L preparative ultracentrifuge with a 40.3 head. The tubes were filled with the solutions prepared in the $25-\mathrm{ml}$ beakers immediately after their preparation and sealed. Centrifugation was carried out at a temperature of 0 to $4^{\circ} \mathrm{C}$ at $40,000 \mathrm{rpm}(114,000 \times g)$ for 22 to 24 hours. Approximately $1.3 \mathrm{ml}$ of the clear and colorless supernatant was removed with a capillary pipette. An exactly measured, usually $1.0-\mathrm{ml}$, portion of this was assayed for ${ }^{64} \mathrm{Cu}$ activity with a portion of each sample before centrifugation.

In preliminary experiments, we found that this relatively long exposure to a high centrifugal force was necesary to sediment into the lower third of the tube serum albumin from a $4 \%$ solution in physiological saline and to obtain a supernatant that remained water clear upon the addition of a $20 \%$ sulfosalicylic acid solution. When samples of human serum were centrifuged under identical conditions, some lipoproteins and chylomicrons were flotated to the surface. The water clear and colorless supernatant that was carefully removed from below this surface layer always showed a very faint opalescence upon the addition of sulfosalicylic acid; thus it contained traces of protein. This, however, was unlikely to be albumin, since the supernatant of a $4 \%$ solution of albumin was protein-free after centrifugation.

We assayed ${ }^{64} \mathrm{Cu}$ activity in a well-type scintillation counter equipped with pulse height analyzer. The counts were corrected for decay on the basis of the 12.8-hour half life of ${ }^{64} \mathrm{Cu}$. The activity found in the supernatant after ultracentrifugal sedimentation of proteins was usually expressed as a percentage of the initial activity in the same solution before ultracentrifugation.

\section{Results}

In the first line of experiments, increasing amounts of labeled copper were added to samples of a $4 \mathrm{~g}$ per $100 \mathrm{ml}$ solution of purified human serum albumin. Ultracentrifugal separation of protein and nonprotein-bound copper was carried out as described in Methods. The percentages of the initial activity remaining in the protein-free supernatant were plotted against the copperalbumin $(\mathrm{Cu} / \mathrm{alb})$ molar ratio in Figure 1 . These 
findings are represented by the crosses, and it can be seen that the percentage of added copper remaining in the supernatant was very low (0.09 to $0.28 \%$ ) at all the tested $\mathrm{Cu} / \mathrm{alb}$ ratios.

The previously described experiment was repeated with native human serum. The results are shown in Figure 1 by the closed circles. At the lower $\mathrm{Cu}$ /alb molar ratios of 0.1 to 0.5 , the percentages of added copper in the supernatant were between two and three times higher than those in the solution of albumin. Between $\mathrm{Cu} / \mathrm{alb}$ molar ratios of 0.5 to 1.5 , the percentages of ${ }^{64} \mathrm{Cu}$ activity in the supernatant of human serum increased very sharply, followed by further slower increases between $\mathrm{Cu}$ /alb molar ratios of 1.5 and 5.0.

The same experiment was also repeated with predialyzed serum (see Methods). These results are represented by the open circles in Figure 1. The percentages of activity remaining in the supernatant in this case were very similar to those observed in a solution of albumin in physiological saline.

The data shown in Figure 1 are derived from two separate experiments involving the use of sera from two different donors and two albumin solutions that were prepared from the same batch of purified human albumin. In each case, however, comparisons were made between native and predialyzed samples of the same serum.

In further experiments of identical design, before the addition of copper, the human serum was dialyzed against a solution of isotonic phosphate

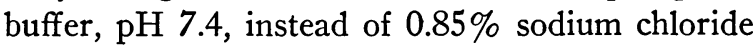
solution as specified above. Similar experiments were carried out with purified serum albumin dis-

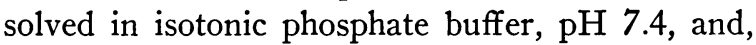
as the final step of purification, dialyzed against the same buffer extensively. The results of these experiments were not significantly different from those shown in Figure 1.

To clarify further the nature of the dialyzable compound or compounds in native human serum that influence the state of copper, we carried out the following experiment. Part of a sample of a freshly obtained normal human serum from a single donor was dialyzed. The dialyzate was lyophilized and taken up in a small volume of ionfree water. Half of the resulting solution was dried in a platinum dish at $95^{\circ} \mathrm{C}$, then ashed by

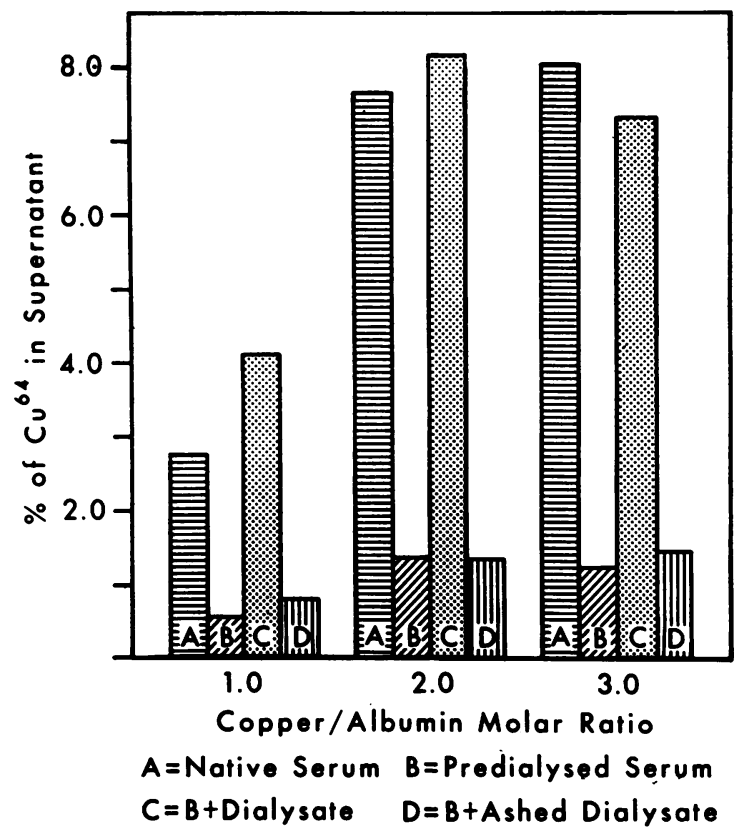

Fig. 2. Per cent of added ${ }^{\text {at }} \mathrm{Cu}$ in the supernatant AFTER ULTRACENTRIFUGAL SEDIMENTATION OF PROTEINS AT CU/AlB MOlar Ratios of 1.0, 2.0, AND 3.0.

ignition followed by 40 hours in a muffle furnace at $300^{\circ} \mathrm{C}$. The residue was cooled and taken up in the same volume of ion-free water. Slight acidification was necessary to achieve near complete dissolution of the residue.

The experiment was then carried out with four types of preparations: $a$ ) native human serum, $b$ ) predialyzed human serum, $c$ ) predialyzed human serum to which dialyzate was added back in amounts necessary to reconstitute the original concentration relationship, and $d$ ) predialyzed human serum that was reconstituted with the ashed dialyzate. Labeled copper was added then to samples of these four preparations in amounts necessary to achieve $\mathrm{Cu} / \mathrm{alb}$ molar ratios of 1.0 , 2.0, and 3.0. After ultracentrifugal sedimentation of the proteins, the supernatants were sampled, and the activity found in the supernatant was expressed as the percentage of the original activity in the samples. The results are shown in Figure 2 .

Dialysis of the serum before addition of the copper led to a marked reduction of the percentage of activity remaining in the supernatant at all three $\mathrm{Cu} /$ alb molar ratios. A marked increase of the activity in the supernatant was observed when 
TABLE II

Effect of amino acids on copper binding by serum proteins*

\begin{tabular}{|c|c|c|c|c|c|c|c|c|}
\hline \multirow{3}{*}{$\begin{array}{l}\text { Copper/albumin } \\
\text { molar ratio }\end{array}$} & \multirow{3}{*}{$\begin{array}{c}\begin{array}{c}\text { Native } \\
\text { serum }\end{array} \\
0\end{array}$} & \multicolumn{4}{|c|}{ Predialyzed serum } & $\begin{array}{l}\text { Native } \\
\text { serum }\end{array}$ & \multicolumn{2}{|c|}{$4 \%$ human albumin } \\
\hline & & \multicolumn{7}{|c|}{ Upper limit of physiological concentration of 21 amino acids added } \\
\hline & & 0 & $1 \times$ & $2 \times$ & $3 \times$ & $1 \times$ & 0 & $1 \times$ \\
\hline 0.1 & 0.51 & 0.22 & 0.67 & & & 1.50 & 0.14 & 1.85 \\
\hline 0.2 & 0.56 & 0.10 & 0.78 & & & 1.40 & 0.28 & 3.07 \\
\hline 2.0 & 7.67 & 0.22 & 9.80 & 19.3 & 27.9 & 15.7 & 0.20 & 13.1 \\
\hline 3.0 & 8.01 & 0.28 & 10.3 & & & 16.1 & 0.10 & 13.1 \\
\hline 4.0 & 8.86 & 0.26 & 11.0 & & & 17.5 & 0.09 & 12.9 \\
\hline
\end{tabular}

* Expressed as per cent of labeled copper remaining in the supernatant.

the dialyzate was added back to the predialyzed serum. When the ashed dialyzate was used to reconstitute the predialyzed serum, the copperbinding characteristics of the predialyzed serum were not affected significantly.

After this, to find out which of the many dialyzable organic constituents influence the state of copper in serum, we added back a number of these constituents one by one to samples of predialyzed serum and assessed their influence on copper binding by the above outlined experimental approach. In the course of this, sodium citrate, lactate, and pyruvate were found to have no significant effect. Oleic, stearic, and linoleic acids in physiological concentration $(0.7 \mathrm{mM})$ and in two times the physiological concentration were ineffectual.

A marked effect on copper binding was obtained, however, when the upper limit of known normal concentrations of 21 free amino acids was reconstituted in predialyzed human serum. The amino acids used and their final concentrations were those shown in Table I, except that cystine and citrulline were omitted in this experiment.

The results are shown in Figure 1 by the closed triangles. It can be seen that the amounts of nonprotein-bound labeled copper in samples of predialyzed human serum with added amino acids are higher than in either the predialyzed human serum or in a $4 \%$ solution of human albumin at all the tested $\mathrm{Cu} /$ alb molar ratios. It is also apparent that the copper-binding characteristics of the predialyzed human serum with added amino acids are very similar to the characteristics of copper binding observed in native human serum.

The numerical results of this latter experiment are shown also in Table II (columns 2 to 4), together with further evidence which indicates that the amount of nonprotein-bound copper in serum varies with the presence or absence of free amino acids, and that the effect of amino acids depends to a considerable extent on their concentrations. This is evident from the data shown in columns 5 and 6 . In this instance, to the same predialyzed human serum as was used in the previous experiment, we added amino acids in amounts necessary to achieve two and three times the upper limit of normal concentrations of amino acids, keeping the protein concentration unaltered. It can be seen that doubling the amino acid concentrations led to a nearly twofold increase in the percentage of ${ }^{64} \mathrm{Cu}$ in the supernatant and tripling it led to a nearly threefold increase. Finally, to a series of samples of the native serum used in this experiment, which presumably contained amino acids in normal concentrations, we added amino acids in amounts used to reconstitute the upper limit of normal concentrations of amino acids in predialyzed serum. In column 7 of Table II, it can be seen that the percentages of added ${ }^{64} \mathrm{Cu}$ remaining in the supernatant in this preparation approximate very closely the sum of the results obtained with the native serum (column 2) and the results obtained with predialyzed serum with once the upper limit of physiological concentration of amino acids added (column 4).

In a further experiment, amino acids were added to a solution of purified human albumin (4 $\mathrm{g}$ per $100 \mathrm{ml}$ ) in physiological saline in amounts sufficient to yield final concentrations of amino acids at the upper limit of known normal concentrations specified in Table I. To a series 


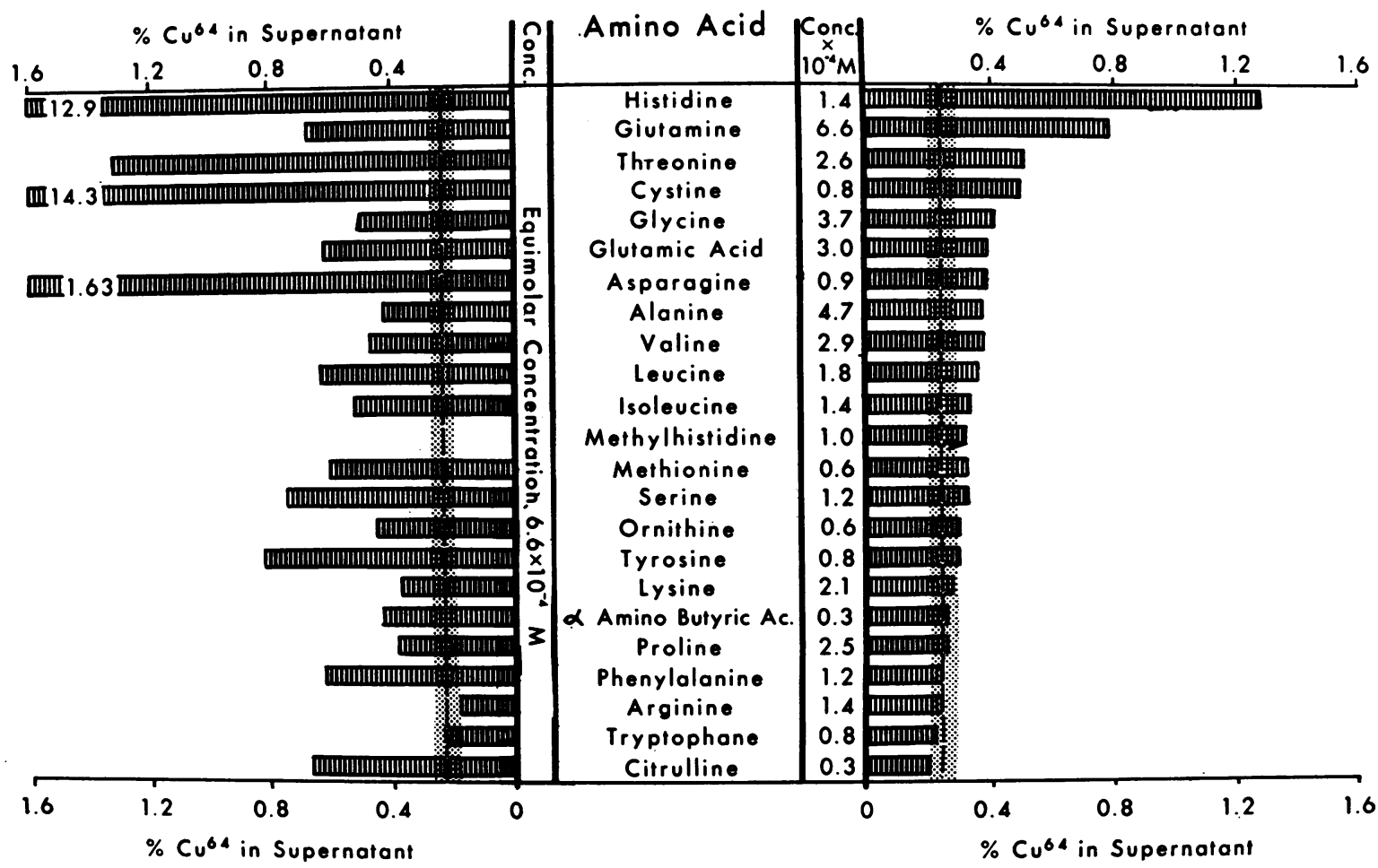

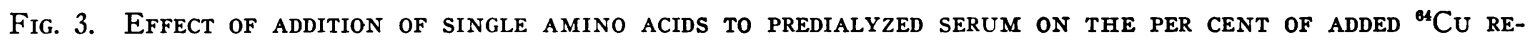

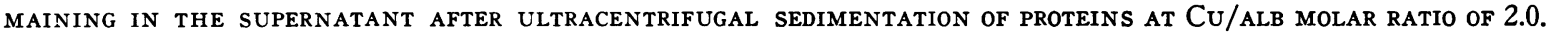
The interrupted line represents the mean and the stippled area the range of the per cent of ${ }^{\text {of }} \mathrm{Cu}$ in the supernatants of five parallel samples of predialyzed serum without addition of amino acids.

of samples of this solution and a series of control samples without added amino acids, we addeci acetate ${ }^{-64} \mathrm{Cu}$ to achieve $\mathrm{Cu}$ /alb molar ratios of 0.1 and stepwise increments to 5.0. In columns 8 and 9 of Table II, it can be seen that, as a result of the addition of amino acids to a solution of purified human albumin, the percentages of ${ }^{64} \mathrm{Cu}$ remaining in the supernatant have increased at all tested $\mathrm{Cu} / \mathrm{alb}$ ratios.

Cystine, cysteine, and citrulline were omitted from our original panel of amino acids. In separate experiments, these amino acids were added one by one together with the previously used panel of 21 amino acids to samples of predialyzed human serum in amounts sufficient to reconstitute the upper limit of normal concentrations. At a $\mathrm{Cu} / \mathrm{alb}$ molar ratio of 2.0 , the addition of these three amino acids did not result in a significant further increase in the percentage of ${ }^{64} \mathrm{Cu}$ activity in the supernatant after ultracentrifugation.

To decide which of the amino acids plays a role in this phenomenon, we added, to a series of sam- ples of predialyzed human serum, single amino acids one by one in amounts sufficient to achieve the upper limits of their normal concentrations (Table I). The serum used in this experiment was a mixture of sera obtained from two healthy adult donors. After the addition of amino acids, labeled copper was added to each sample to reach a $\mathrm{Cu} /$ alb molar ratio of 2.0. After ultracentrifugation, the ${ }^{64} \mathrm{Cu}$ activity in the supernatant was measured. The results are shown in the right half of Figure 3.

The amino acids are listed in decreasing order of the magnitude of their effect. The horizontal bars represent the percentage of ${ }^{64} \mathrm{Cu}$ activity remaining in the supernatant. The stippled area represents the range of the percentages of ${ }^{64} \mathrm{Cu}$ activity found in the supernatants of five parallel samples of the same predialyzed serum to which amino acids were not added. The interrupted line drawn at $0.24 \%$ represents the mean of these five individual observations. The effect of the amino acids in altering the state of copper in predialyzed 
serum is represented by the increment in the percentage of ${ }^{64} \mathrm{Cu}$ in the supernatant over the percentage in the supernatant of the predialyzed serum (interrupted line).

It can be seen that at least half of the 23 amino acids had significantly altered the binding of copper to serum proteins. Histidine proved to have the most marked effect. In the presence of this amino acid alone, the percentage of ${ }^{64} \mathrm{Cu}$ in the supernatant was 5.4 times higher than in the predialyzed serum without added amino acids. The next was glutamine, with a 3.3 times higher percentage of ${ }^{64} \mathrm{Cu}$ in the supernatant than in predialyzed serum. Threonine and cystine followed, with more than double the amount in the supernatant. In the presence of physiological concentrations of glycine, glutamic acid, asparagine, alanine, valine, leucine, and isoleucine, there was a noticeable effect on copper binding, but the percentage of ${ }^{64} \mathrm{Cu}$ in the supernatant was less than twice that found in the predialyzed serum. In the rest of the amino acids, the effect was either of questionable significance or absent.

In a parallel experiment, amino acids were added singly to a series of samples of the same mixture of predialyzed human sera from two donors in equimolar concentration. The concentration arbitrarily chosen was that of glutamine in the previous experiment $\left(6.6 \times 10^{-4} \mathrm{M}\right)$. The results are shown in the left half of Figure 3. Mole per mole, cystine appeared to have the most marked effect on the protein binding of copper, closely followed by histidine. Asparagine and threonine were next, followed by tyrosine, serine, glutamine, phenylalanine, glutamic acid, leucine, methionine, and others. Of the 23 amino acids, only arginine and tryptophan appeared to have no noticeable effect at this concentration.

Cysteine was also tested in this experiment (not shown in Figure 3 ). Its addition to predialyzed human serum in a $6.6 \times 10^{-4} \mathrm{M}$ concentration resulted in the finding of about one-half the ${ }^{64} \mathrm{Cu}$ in the supernatant as was found with cystine in the same molar concentration. This suggests that under the conditions of these experiments, the cysteine was rapidly oxidized to cystine and acted as cystine.

We repeated the above experiments with single amino acids added to predialyzed human serum in both physiological and equimolar concentrations with most of the amino acids on two to five occasions using serum from different normal human donors. The results of these experiments were not substantially different from those shown in Figure 3.

The results of the experiments outlined above are compatible with the assumption that a substantial number of the amino acids that are normally present in human serum are effectively competing with albumin for the binding of copper and that the resulting complexes between amino acids and copper escape ultracentrifugal sedimentation. One may suppose, then, that when all these amino acids are present in the same sample of serum, they will still compete individually with albumin for copper. Consequently, the total amino acidbound fraction of copper in this latter case may be close to the sum of their individually observed bindings.

To test the validity of this thesis, we included three control samples in the experiment in which the effect of the presence of physiological concentrations of individual amino acids was tested on copper binding. These were two parallel samples each of $a$ ) the same native serum, $b$ ) the same predialyzed serum to which amino acids were not added, and $c$ ) the same predialyzed serum to which all 23 amino acids were added simultaneously in amounts necessary to reconstitute the upper levels of their normal concentrations. To these control samples, we added labeled copper acetate to achieve $\mathrm{Cu} / \mathrm{alb}$ molar ratios of 2.0 , similar to all the rest of the series of samples that contained the predialyzed serum with individual amino acids in the same physiological concentrations added (right half of Figure 3 ).

In Figure 4, the top three horizontal bars represent the results of the three controls in terms of the mean percentage of added ${ }^{64} \mathrm{Cu}$ remaining in the supernatant after ultracentrifugal sedimentation of proteins. The fourth horizontal bar represents the sum of the percentages of ${ }^{64} \mathrm{Cu}$ in the supernatant of samples to which amino acids were added individually. This sum was calculated by taking the percentage of ${ }^{64} \mathrm{Cu}$ remaining in the supernatant in the case of each individually added amino acid (shown in the right half of Figure 3), subtracting from each the percentage 


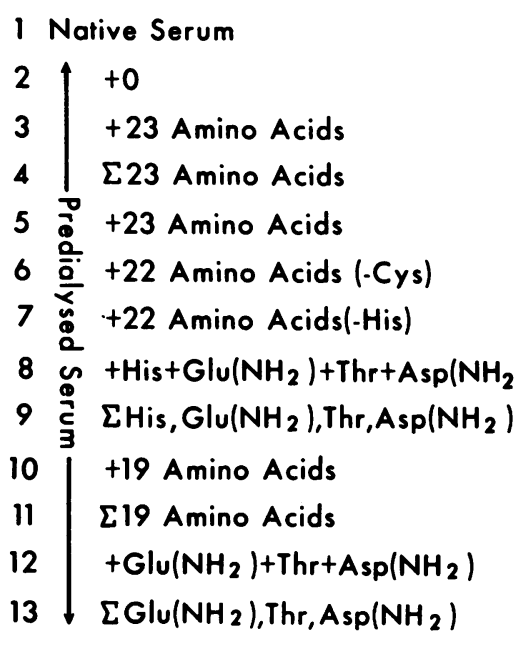

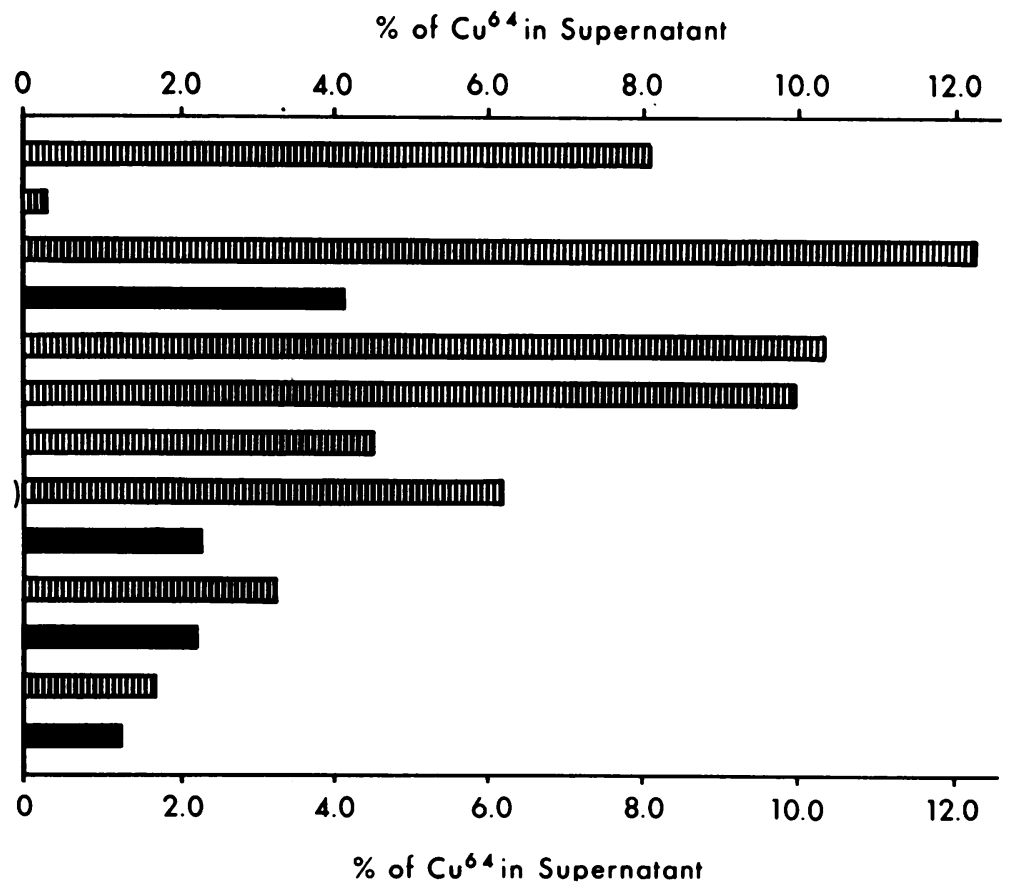

Fig. 4. EFFECTS OF ADDITIONS OF AMINo ACIDS IN VARIOUS COMBINATIONS TO SAMPLES OF PREDIALYZED SERUM COMPARED TO THE SUM OF THEIR INDIVIDUAL EFFECTS. Cu/alb molar ratio $=2.0 ; \Sigma=$ sum of individual effects; cys $=$ cystine; his = histidine; glu $\left(\mathrm{NH}_{2}\right)=$ glutamine; thr $=$ threonine; asp $\left(\mathrm{NH}_{2}\right)=$ asparagine. Striped bars represent combined addition of amino acids. Solid bars represent sums of individual effects.

of ${ }^{64} \mathrm{Cu}$ in the supernatant of the predialyzed serum (0.24), and taking the sum of these differences and adding the percentage in the supernatant of the predialyzed serum only once. This sum is represented by the closed horizontal bar in line 4 of Figure 4. It can be seen that this sum of the individual effects is only one-third the effect of the combined addition of the same amino acids (line 3, Figure 4).

We then attempted to find out which amino acids may be responsible for this unusual effect on the state of copper, which appears when they are simultaneously present in this system. It was thought that the amino acids which exhibited the highest degree of copper binding in competition with albumin may be responsible. Therefore, from our panel of 23 amino acids, first cystine and then histidine was omitted. The other 22 amino acids were added to samples of predialyzed serum. Since this was a separate experiment, a control sample was included to which all 23 amino acids were added, including both cystine and histidine. The final concentration of added amino acids was the upper limit of their physiological concentration
(Table I). Labeled copper was added to achieve a $\mathrm{Cu}$ /alb molar ratio of 2.0 , and the samples were subjected to ultracentrifugation. The results are shown in Figure 4 in lines 5 to 7 . Omission of cystine from the panel of 23 amino acids had no significant effect on the percentage of amino acidbound copper in the supernatant (line 6 compared to line 5 in Figure 4). When, however, histidine was omitted, there was a very marked decrease from $10.45 \%$ (line 5 ) to $4.51 \%$ (line 7 ). The addition of histidine alone to a sample of predialyzed serum resulted in an increment of $1.0 \%$ of ${ }^{64} \mathrm{Cu}$ in the supernatant (see Figure 3). On the other hand, in this latter experiment, the omission of histidine from the panel of 23 amino acids resulted in a $5.8 \%$ decrease of ${ }^{64} \mathrm{Cu}$ in the supernatant.

From this, it seemed reasonable to conclude that histidine in combination with one or more amino acids is responsible for the observed paradoxical effect. We designed experiments to determine which other amino acids are involved in this phenomenon. To a series of samples of a predialyzed human serum, histidine was added in combination 
TABLE III

\begin{tabular}{|c|c|c|c|}
\hline Group & $\begin{array}{l}\text { Amino acid in } \\
\text { with hi }\end{array}$ & $\begin{array}{l}\text { ombination } \\
\text { dine }\end{array}$ & $\begin{array}{c}\begin{array}{c}\text { Ratio of per cent of } \\
64 \mathrm{Cu} \text { in supernatant: } \\
\text { Combined addition }\end{array} \\
\text { Sum of individual effects }\end{array}$ \\
\hline A & $\begin{array}{l}\text { Asparagine } \\
\text { Threonine }\end{array}$ & Glutamine & $2.1-2.4$ \\
\hline B & $\begin{array}{l}\text { Serine } \\
\text { Alanine }\end{array}$ & $\begin{array}{l}\text { Valine } \\
\text { Glutamic acid }\end{array}$ & $1.5-1.8$ \\
\hline $\mathrm{C}$ & $\begin{array}{l}\text { Citrulline } \\
\text { Lysine } \\
\text { Arginine } \\
\text { Leucine } \\
\text { Ornithine } \\
\text { Cystine } \\
\alpha \text {-Amino butyric } \\
\quad \text { acid }\end{array}$ & $\begin{array}{l}\text { Proline } \\
\text { Tryptophan } \\
\text { Glycine } \\
\text { Isoleucine } \\
\text { Phenylalanine } \\
\text { Methionine }\end{array}$ & 1.3 or less \\
\hline
\end{tabular}

with only one of each of the other 22 amino acids, all of which were added in physiological concentrations. The percentage of ${ }^{64} \mathrm{Cu}$ in the supernatant of these samples was then compared to the sum of the individual effects of histidine and the amino acid in question.

The results of this experiment are summarized in Table III. The amino acids, when tested in combination with histidine, fell into three groups. Asparagine, glutamine, and threonine (group A), in combination with histidine, were able to bind more than twice as much copper as the sum of their individual effects. Serine, valine, alanine, and glutamic acid (group B) in combination with histidine held significantly more copper than they did individually. The rest of the amino acids (group C) in combination with histidine showed either minimal increase in binding or no increase at all.

After this, the effect of the combined presence of the physiological concentrations of four amino acids was tested in predialyzed serum. In this experiment, histidine was combined with the three amino acids that appeared to have the most marked effect in combination with histidine, namely asparagine, glutamine, and threonine (group A, Table III). In the presence of the physiological concentrations of these four amino acids, a considerable percentage of the added ${ }^{64} \mathrm{Cu}$ $(6.22 \%)$ remained in the supernatant. This is shown in Figure 4, line 8 . The sum of the individual effects of these four amino acids is much lower $(2.26 \%)$; this is shown by the closed bar in line 9 of Figure 4. As a corollary, the upper limits of physiological concentrations of the 19 remaining amino acids were reconstituted in predialyzed serum (the panel of amino acids listed in Table I minus histidine, glutamine, asparagine, and threonine). In this experiment, $3.23 \%$ of the added ${ }^{64} \mathrm{Cu}$ remained in the supernatant (see line 10, Figure 4). These 19 amino acids apparently bind only one-third of the total amino acidbound fraction of copper; the other two-thirds is bound by histidine, threonine, glutamine, and asparagine.

By adding the effect of the combined presence of the four amino acids (line 8 , Figure 4 ) to the effect of the 19 remaining amino acids (line 10 , Figure 4), one obtains 9.45 , which is quite close to the effect of the combined presence of all 23 amino acids in the same predialyzed serum, 10.34 (line 5, Figure 4).

In Figure 4, the closed bars in lines 9 and 11 represent the sums of individual effects of the four amino acids and the 19 amino acids, respectively. It can be seen that in the combined presence of the four amino acids (line 8), the percentage of copper in the supernatant is nearly three times higher than the sum of their individual effects (line 9). On the other hand, although the percentage of ${ }^{64} \mathrm{Cu}$ in the supernatant in the combined presence of the 19 remaining amino acids is still higher than the sum of their individual effects, the ratio in this case amounts to only 1.5.

Finally, in an attempt to show the key position of histidine in this scheme, we measured the effects of combined additions of glutamine, threonine, and asparagine. The results are shown in line 12 of Figure 4 . Comparison of this effect $(1.67 \%)$ with the effect of histidine together with the same three amino acids $(6.22 \%$, line 8 of Figure 4) reveals the extraordinary position that histidine occupies in this system. The closed bar in line 13, Figure 4, shows the sum of the individual effects of the same three amino acids, the combined effects of which are shown in line 12 . This is less than their combined effect, but the difference is small. The ratio between them is only 1.3 , whereas the ratio in the presence of the same three amino acids plus histidine was 2.75 .

In the experiments described above, the $\mathrm{Cu} / \mathrm{alb}$ 
molar ratios were far in excess of the physiological range. The mean concentration of nonceruloplasmin-bound copper in normal adult human sera is $7 \mu \mathrm{g}$ per $100 \mathrm{ml}$ (3), which, in the presence of an average normal concentration of albumin $(4 \mathrm{~g}$ per $100 \mathrm{ml}$ ), amounts to a $\mathrm{Cu} / \mathrm{alb}$ molar ratio of 0.002. Additional studies were performed, therefore, in which the concentrations of nonceruloplasmin-bound copper were kept within the physiological range.

Four separate experiments were carried out with sera from five normal individuals. Samples of native serum, predialyzed serum, and predialyzed serum with amino acids added in physiological concentrations were used in parallel. A ${ }^{64} \mathrm{Cu}$ preparation of high specific activity was added to these samples $a$ ) in trace amounts, which did not exceed $1 \%$ of the total copper in the nonceruloplasmin-bound compartment; $b$ ) in amounts sufficient to increase the copper in this compartment by $50 \%$; and $c$ ) by $250 \%$. Since accurate measurement of the nonceruloplasmin-bound fraction of copper in an individual human serum is not possible by available methods, we assumed that the normal human sera used in these experiments contained the average normal amounts of nonceruloplasmin-bound copper, $7 \mu \mathrm{g}$ per $100 \mathrm{ml}$ (3). It has been shown that only an insignificant portion of this copper is dialyzable ( 7$)$; therefore, we assumed that the predialyzed serum contained the same amount of copper. Thus, the nonceruloplasmin-bound copper concentrations in these sera were $7,10.5$, and $25.5 \mu \mathrm{g}$ per $100 \mathrm{ml}$, amounting to approximate $\mathrm{Cu} / \mathrm{alb}$ molar ratios of $0.002,0.003$, and 0.007 .

The results of these experiments are summarized in Figure 5, where the percentages of added ${ }^{64} \mathrm{Cu}$ remaining in the supernatant after ultracentrifugal sedimentation of proteins are shown in the three types of serum preparations, each at three different $\mathrm{Cu}$ /alb molar ratios. By using Student's $t$ test $(13,14)$, we found that the differences between the means at the three different $\mathrm{Cu} / \mathrm{alb}$ molar ratios with the same type of serum preparation were not significant ( $p=0.2$ to 0.9 ). Therefore, the data pertaining to the three different amounts of added copper were combined for each of the three serum preparations and the over-all means and their standard deviations calculated.

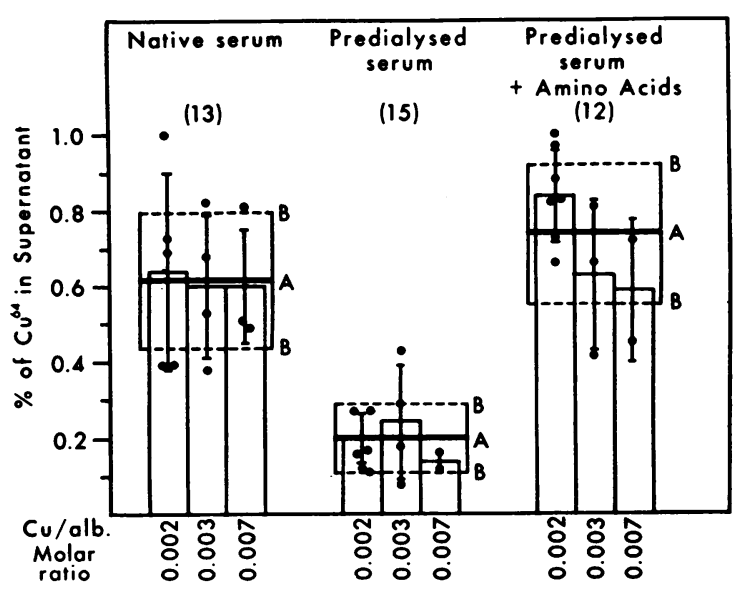

Fig. 5. Per cent of added ${ }^{64} \mathrm{CU}$ in the supernatant AFTER ULTRACENTRIFUgal SEDIMENTATION OF PROTEINS AT Physiological CU/Alb molar Ratios in Native SERUM, PREDIALYZED SERUM, AND PREDIALYZED SERUM WITH ADDED AMINo ACIDS. Closed circles represent the individual observations. Open columns denote the means at the different $\mathrm{Cu} / \mathrm{alb}$ ratios. The vertical lines across these show the range of $1 \mathrm{SD}$. Horizontal lines $\mathrm{A}$ indicate the over-all means obtained by combining the individual results at the three $\mathrm{Cu} / \mathrm{alb}$ ratios; the number of individual observations from which these means were calculated are shown in parentheses. Interrupted horizontal lines $\mathrm{B}$ show the range of $1 \mathrm{SD}$ of the over-all means.

These are shown in Figure 5 by the horizontal lines marked $\mathrm{A}$ and $\mathrm{B}$, respectively. It can be seen that, in predialyzed sera, the over-all mean percentage of ${ }^{64} \mathrm{Cu}$ remaining in the supernatant is much lower than in the native serum. This difference is highly significant $(p<0.001)$. Reconstitution of the normal amino acid levels in predialyzed serum resulted in a significant rise in the percentage of ${ }^{64} \mathrm{Cu}$ remaining in the supernatant $(p<0.001)$. The difference between the over-all mean percentage of ${ }^{64} \mathrm{Cu}$ in native serum and predialyzed serum with added amino acids is not significant $(\mathrm{p}>0.1)$.

From these results, the conclusion can be drawn that a low but significant percentage of nonceruloplasmin-bound copper at physiological concentrations in serum is bound to amino acids.

\section{Discussion}

According to the results presented in this paper, a fraction of copper in human serum remained in the supernatant after exposure to a centrifugal force that was shown to sediment albumin effec- 
tively. The amount of this nonprotein-bound form of copper in native human serum varies with the total amount of nonceruloplasmin-bound copper in the serum; in broad terms, the more copper added, the more in the fraction that escapes ultracentrifugal sedimentation.

It has also been shown that low molecular weight dialyzable solutes in serum influence the degree of complexing of copper with albumin and that in their presence, the nonprotein-bound fraction of copper is increased significantly. The finding that ashing destroys the effective constituents of the dialyzate of serum suggests that these components are organic in nature.

In further experiments, we found that most, if not all, the effect on the state of copper on the part of dialyzable components of serum could be ascribed to free amino acids, which are normally present in serum. The property of amino acids to readily form various complexes with cupric ions is well known (15). Considering this, it seems logical to assume that amino acids may effectively compete for the binding of copper with albumin according to the following equilibrium equations : 1) albumin $+\mathrm{Cu}^{++} \rightleftarrows$ albumin-copper complex; 2) amino acids $+\mathrm{Cu}^{++} \rightleftarrows$ amino acid-copper complexes; 3) albumin-copper complex + amino acids $\rightleftarrows$ albumin + amino acid-copper complexes. The relationship found in this study between the concentrations of amino acids and the amounts of ultracentrifugally nonsedimentable fraction of copper shown in Table II is compatible with the existence of the equilibrium described by the third equation.

Further experiments revealed that a relatively large number of the amino acids have the property of effectively competing with albumin for the binding of copper and that they are different in respect to the extent to which they are able to compete. Their effect also depends to a considerable extent on their concentrations.

A rather surprising finding was that when all or most of the normally occurring amino acids were present in serum simultaneously in physiological concentrations, they were apparently binding a much larger portion of the nonceruloplasmin-bound copper in serum than would be expected on the basis of their individual binding capacities. A possible explanation may be that, in addition to the complexes of single amino acids with copper, so-called mixed amino acid-copper complexes are formed, which consist of one atom of copper and two different amino acids. These complexes may hold significant additional amounts of copper in competition with albumin and individual amino acids, provided their association constants are as high as or higher than those of simple amino acid-copper complexes.

Martin and Pâris have reported recently the formation of mixed complexes by two different amino acids and divalent copper in vitro $(16,17)$. They have studied the properties of mixed complexes such as glycine-copper-alanine, glycinecopper-tyrosine, and alanine-copper-tyrosine, and compared these to the properties of the simple complexes, glycine-copper, alanine-copper, and tyrosine-copper. The dissociation constants of the mixed complexes were very similar and certainly not lower than those of the simple complexes.

From the results obtained in this study, it would seem that, under normal circumstances, the quantitatively important mixed complexes contain histidine as one of the amino acids. The amino acids that preferentially form mixed copper complexes with histidine are threonine, glutamine, and asparagine. Nevertheless, in addition to these, a number of other amino acids may be involved in mixed complex formation with histidine to a lesser extent (those listed in Table III, group B).

Admittedly, the results of investigations presented here do not do more than suggest evidence in favor of the above considerations. Whereas there may be little doubt left concerning the existence of a third low molecular weight fraction of copper in serum that is in equilibrium with copper bound to albumin, definite proof of the existence of copper-amino acid complexes will have to come from isolation and characterization of such complexes in serum.

Since the completion of the studies reported here, Sarkar and Kruck have successfully separated and characterized copper-amino acid complexes from ultrafiltrates of human sera by thin layer chromatography. They identified simple complexes of histidine-copper, threonine-copper, and glutamine-copper and, in addition, a mixed complex of histidine-copper-threonine (18). 
On the basis of the experimental results which were presented here, certain conclusions can be drawn concerning the copper-binding characteristics of human serum albumin.

To allow more meaningful analysis of the results presented in Figure 1, these data were recalculated to yield the actual molar concentration of copper remaining in the supernatant after ultracentrifugal sedimentation of proteins at various copper-albumin ratios. This requires the assumption that complete mixing has occurred and that the specific activities of the copper bound to albumin and that in the supernatant were the same. It should be noted that, in these experiments, the concentrations of albumin and those of amino acids when present were constant, and the concentrations of copper were varied. These calculations were made in native serum, predialyzed serum, and the solution of purified human serum albumin. In Figure 6, the copper concentrations in the supernatant were plotted on the vertical axis against the initial copper albumin molar ratios on the horizontal axis.

In section $A$ of Figure 6 , the data obtained in native serum are shown. The points seem to fall on two straight lines, which cross at a $\mathrm{Cu} / \mathrm{alb}$ molar ratio of about 0.7 . At lower $\mathrm{Cu} / \mathrm{alb}$ molar ratios, with increasing amounts of added copper, the concentrations of copper remaining in the supernatant rise rather slowly, whereas past this point, with further increases in total copper concentration, there is a much more pronounced rise in the concentration of copper in the supernatant. A very similar situation exists in both the predialyzed serum and a solution of human albumin. This is shown in section B of Figure 6. Here, because of the absence of amino acids, the concentrations of copper in the supernatant were much lower; this made it necessary to change the scale on the vertical axis. Nevertheless, the same phenomenon is clearly shown; the points seem to fall close to two straight lines which intersect somewhat below a $\mathrm{Cu} / \mathrm{alb}$ molar ratio of 1.0 .

The conclusion can be drawn from these findings that the first binding site for copper on albumin is different from the second. This same conclusion was made by Breslow in the case of bovine albumin and in the $\mathrm{pH}$ range of 6.5 to 9.0 , on the

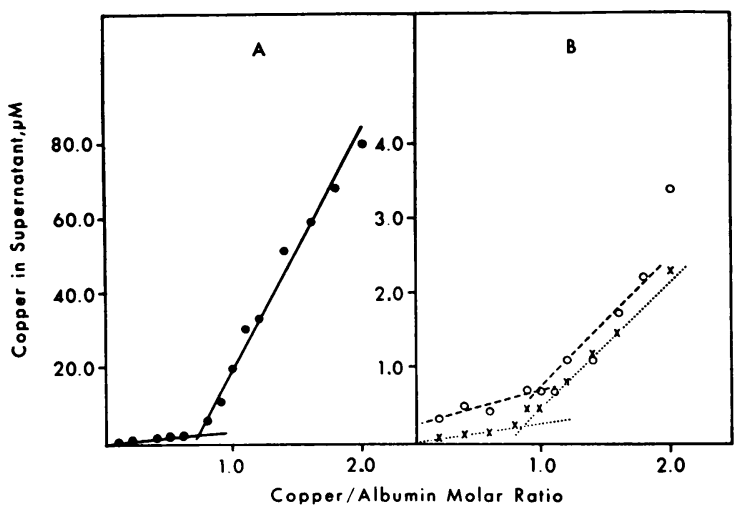

Fig. 6. Concentration of COpPer (Micromoles Per LITER) IN THE SUPERNATANT AFTER ULTRACENTRIFUGAL SEDIMENTATION OF PROTEINS PLOTTED AGAINST THE INITIAL MOLAR RATIO BETWEEN COPPER AND ALBUMIN. = native serum; $X=$ predialyzed serum; $O=4 \mathrm{~g}$ per $100 \mathrm{ml}$ solution of human albumin. Note that in $A$ and $B$ the vertical scale is different.

basis of measurements of proton displacement (19). The studies presented here confirm Breslow's findings and suggest that the same situation exists in human albumin. In addition to this, it seems obvious that the first binding site for copper on albumin has a higher affinity for copper than the second; this is evident both in the presence and in the absence of a second ligand for copper (amino acids).

It may seem pertinent to consider the stoichiometric relation in serum between copper on the one hand and albumin and amino acids on the other. The normal concentration of nonceruloplasmin-bound copper in serum is considered to be $7 \mu \mathrm{g}$ per $100 \mathrm{ml}$ (3) or $1.1 \mu$ atoms per L. The albumin concentration is around $4 \mathrm{~g}$ per $100 \mathrm{ml}$ or 0.6 mmole per $\mathrm{L}$; this latter concentration is three orders of magnitude higher than the nonceruloplasmin-bound copper concentration. The total molarity of amino acids in serum is approximately 60 mmoles per L, which is four to five orders of magnitude higher than the concentration of copper. The normal concentration of histidine, the amino acid primarily involved in the binding of copper, is 1.4 mmole per $\mathrm{L}$, three orders of magnitude higher than the concentration of copper. This serves to show that the concentration of ligands, both albumin and amino acids, exceeds by far the concentration of the metal; therefore, in the case of a tenfold or even hundredfold in- 
crease in the concentration of copper, which will perhaps never occur under normal or even pathological conditions, the available concentration of ligands exceeds by far the concentration of copper.

Finally, consideration should be given to the possible physiological role of the amino acidbound fraction of serum copper. It would seem logical to assume that this low molecular weight form of copper that is in equilibrium with the larger albumin-bound pool in the same compartment may have a role in the transport of copper between the blood and the tissues. The great bulk of copper is protein bound, both in the plasma and intracellular compartments. The equilibration between these two compartments must occur through the capillary and the cell membranes, and it would seem logical to assume that amino acids, which are capable of binding some copper in competition with albumin in the plasma and perhaps also in competition with copper-binding proteins in the cells, may mediate, by virtue of their small molecular size, the transport of copper to or through membranes. Results of experiments that lend support to this thesis will be presented in separate publications $(20,21)$.

\section{References}

1. Holmberg, C. G., and C. B. Laurell. Investigations in serum copper. II. Isolation of the copper containing protein and a description of some of its properties. Acta chem. scand. 1948, 2, 550.

2. Gubler, C. J., M. E. Lahey, G. E. Cartwright, and M. M. Wintrobe. Studies on copper metabolism. IX. The transportation of copper in blood. J. clin. Invest. 1953, 32, 405.

3. Cartwright, G. E., and M. M. Wintrobe. Copper metabolism in normal subjects. Amer. J. clin. Nutr. 1964, 14, 224.

4. Sternlieb, I., A. G. Morell, W. D. Tucker, M. W. Greene, and I. H. Scheinberg. The incorporation of copper into ceruloplasmin in vivo: studies with copper $^{84}$ and copper ${ }^{87}$. J. clin. Invest. 1961, 40, 1834.

5. Bearn, A. G., and H. G. Kunkel. Localization of $\mathrm{Cu}^{64}$ in serum fractions following oral administration: an alteration in Wilson's disease. Proc. Soc. exp. Biol. (N. Y.) 1954, 85, 44.

6. Scheinberg, I. H., and I. Sternlieb. Copper metabolism. Pharmacol. Rev. 1960, 12, 355.
7. Earl, C. J., M. J. Moulton, and B. Selverstone. Metabolism of copper in Wilson's disease and in normal subjects: studies with $\mathrm{Cu}-64$. Amer. J. Med. 1954, 17, 205.

8. Weichselbaum, T. E. An accurate and rapid method for the determination of proteins in small amounts of blood serum and plasma. Amer. J. clin. Path. 1946, 16, tech. sect. 40.

9. Orlandini, O. T., A. Sass-Kortsak, and J. H. Ebbs. Serum gamma globulin levels in normal infants. Pediatrics 1955, 16, 575.

10. Eden, A., and H. H. Green. Micro-determination of copper in biological material. Biochem. J. 1954, $34,1202$.

11. Stein, W. H., and S. Moore. The free amino acids of human blood plasma. J. biol. Chem. 1954, 211, 915.

12. Fritze, K. The preparation of high specific activity copper 64. Radiochim. Acta 1964, 3, 166.

13. Gosset, W. S. The probable error of a mean (by "Student"). Biometrika 1908, 6, 1.

14. Fisher, R. A. On a distribution yielding the error functions of several well-known statistics. Proceedings of the International Mathematical Congress (Toronto), 1924, S. C. Fields, Ed. Toronto, University of Toronto Press, 1928, vol. 2, p. 805.

15. Greenstein, J. P., and M. Winitz. Chemistry of the Amino Acids. New York, John Wiley and Sons, 1961, vol. 1, p. 569.

16. Martin, R.-P., and R. A. Pâris. Stabilité et isolement de quelques chélates mixtes de cuivre. C. R. Acad. Sci. (Paris) 1963, 257, 3932.

17. Martin, R.-P., and R. A. Pâris. Variation, en fonction de la force ionique, des constantes de stabilité des chélates simples et mixtes du cuivre avec la glycine et l'alanine. C. R. Acad. Sci. (Paris) 1964, 258, 3038.

18. Sarkar, B., and T. P. A. Kruck. Copper-amino acid complexes in human serum in Biochemistry of Copper, J. Peisach, P. Aisen, and W. E. Blumberg, Eds. New York, Academic Press, 1966, p. 183.

19. Breslow, E. Comparison of cupric ion-binding sites in myoglobin derivatives and serum albumin. $\mathrm{J}$. biol. Chem. 1964, 239, 3252.

20. Harris, D. M., and A. Sass-Kortsak. The influence of amino acids on copper uptake by rat liver slices. J. clin. Invest. 1967, 46, 659.

21. Neumann, P. Z., R. Smuckler, and A. Sass-Kortsak. Role of amino acids in copper transport. Facilitation of transfer through semipermeable membranes and uptake by red blood cells. In preparation. 